\title{
The Sexual Psychopath Act In Practice: A Critical Discussion
}

\author{
Frederick J. Hacker* and Marcel Frym**
}

I

GENERAL CONSIDERATIONS

California, and an increasingly large number of other states in the United States, ${ }^{1}$ have passed special statutes in the last 18 years, dealing with so-called "psychopathic" sexual offenders, and several more states are at present considering the legislative passage of similar laws. To a certain extent, this legislation is the result of the insistent demands on the part of medical and legal leaders, as well as some enlightened civic groups, who were convinced that the commission of a sex crime was usually, if not always, evidence of a mental disorder which should be treated rather than punished.

A. Edward Nichols, former Legal Advisor to the Department of Mental Hygiene of the State of California, has said of the sexual psychopath laws that

[they are] curative and remedial means of treating the sexually deviated offender by way of psychiatric approach, and the entire theme [of the legislation] was that the individual should be committed to a State Mental Hospital where he could receive psychiatric treatment. ${ }^{2}$

This type of legislation definitely established the progressive precedent that mental illness, even if it did not meet the criteria of the "right or wrong" test of the obsolete $M$ 'Naghten rule about insanity, is to be recognized as a condition that requires special treatment somewhat different fron the customary penal law enforcement procedure. Therefore, the introduction of this legislation was hailed by practically all scientists and many enlightened judges, law enforcement officers, and parts of the community as a major step forward. Finally the principle seemed to have been

*M.D., Practicing Psychiatrist and Psychoanalyst, Chief of Staff, Hacker Psychiatric Clinic, Beverly Hills, California.

**J.D., Director of Criminological Research, Hacker Foundation for Psychiatric Research, Beverly Hills, California.

1 At present, the following jurisdictions have passed sexual psychopath laws: Alabama, California, Illinois, Indiana, Massachusetts, Michigan, Minnesota, Missouri, New Hampshire, New Jersey, New York, Ohio, Pennsylvania, Vernont, Virginia, Washington, Wisconsin, and District of Columbia.

2 Unpublished address by A. Edward Nichols dehivered at Norwalk State Hospital (now Metropolitan State Hospital), Norwalk, California, May 22, 1952 (hereinafter cited as ADDREss). 
recognized and adopted that "our collective conscience does not allow punishment where it cannot impose blame."3

However, an even more important factor in the enactment of such legislation was the ever-growing preoccupation of powerful and vociferous parts of the population with sex crimes. The demands of the "people's voice," occasionally couched in rational argument but more often expressed with hysterical fervor, for more restrictive measures against sex criminals had to be met somehow by the various legislatures, since important groups seemed to feel that ordinary legislation was not sufficient to protect the community from the perpetration and repetition of heinous crimes by sex fiends. The sexual psychopath laws seemed to serve admirably this purpose of added protection. They provided for prolonged and sometimes indefinite confinement of the culprit in a closed, maximum security mstitution, where the offender was supposed to receive psychological, psychiatric, or any other type of medical treatment from which he could benefit. This kind of legislation thus seemed most felicitous in that it satisfied the diverse strivings and tendencies of both the treatment-minded and the punishmentminded.

Yet, after many years' observation of the functioning of these laws, personal and professional acquaintance with hundreds of offenders, as well as participation in dozens of trials under the Sexual Psychopath Act, the authors feel very definitely that this legislation has neither in practice nor in theory lived up to the high expectations attached to it at its inception. This conclusion appears inevitable, notwithstanding the fact that in Southern Califorma, where our observations have taken place, sex offenders have been interned in an excellent state institution administered by highly qualified psychiatrists under the guidance of an outstanding, unusually humane, and understanding superintendent. Even the high professional and human caliber of the medical administrators of this act has not significantly mitigated the shortcomings intrinsically contained in this legislation.

In the following we will attempt to show the various reasons for the ineffectiveness of sexual psychopath legislation and will attempt to make certain recommendations and suggestions for a remedy.

The California Sexual Psychopath Act was put imto existence in 1939, with important changes made several times, particularly in 1949, 1950, 1952 , and $195 .^{4}$ According to Mr. Nichols, at first only a relatively small number of defendants availed themselves of the provisions of this act. Those who did used it "to a very great extent as a means or device for

${ }^{3}$ See Holloway v. United States, 148 F.2d 665, 666-67 (D.C. Cir. 1945).

4 The act is contained in CAI. WeLr. \& INST. Code $\$ \S 5500-21$. The 1955 changes, while important, do not affect the thesis of this article. 
avoiding being sentenced to State Prison." 5 This made a revision imperative. The Sexual Psychopath Act, as amended repeatedly in somewhat confusing ways, now essentially states the following:

"[S] exual psychopath" means any person who is affected, in a form predisposing to the commission of sexual offenses, and in a degree constituting him a menace to the health or safety of others, with any of the following conditions:

(a) Mental disease or disorder.

(b) Psychopathic personality.

(c) Marked departures from normal mentality. ${ }^{6}$

When a person is convicted of any criminal offense, whether or not a sex offense, the trial judge, on his own motion, or on motion of the prosecuting attorney, or on application by affidavit by or on behalf of the defendant, if it appears to the satisfaction of the court that there is probable cause for believing such person is a sexual psychopath ..., may adjourn the proceeding or suspend the sentence, as the case may be, and may certify the person for hearmg and examination by the superior court of the county to determine whether the person is a sexual psychopath ....

When a person is convicted of a sex offense involving a child under 14 years of age and it is a misdemeanor, and the person has been previously convicted of a sex offense in this or any other state, the court shall adjourn the proceeding or suspend the sentence, as the case may be, and shall certify the person for hearing and examination by the superior court of the county to determine whether the person is a sexual psychopath ....

When a person is convicted of a sex offense involving a child under 14 years of age and it is a felony, the court shall adjourn the proceeding or suspend the sentence, as the case may be, and shall certify the person for hearing and examination by the superior court of the county to determine whether the person is a sexual psychopath .... ${ }^{7}$

In all these instances:

The judge shall appoint not less than two nor more than three psychiatrists, each of whom shall be a holder of a valid and unrevoked physician's and surgeon's certificate who has directed his professional practice primarily to the diagnosis and treatment of mental and nervous disorders for a period of not less than five years, and at least one of whom shall be from the medical staff of a State lrospital or county psychopathic hospital, to make a personal examination of the alleged sexual psychopath, directed toward ascertaining whether the person is a sexual psychopath. ${ }^{8}$

After psychiatric examinations have been made, and findings reported to the court, the sexual psychopathy hearing is held.

If, after examination and hearing, the judge finds that the person is a sexual psychopath ..., he shall make and sign an order that the person be placed temporarily in a suitable psychiatric facility maintained by a county or in

\footnotetext{
5 NICHOTS, ADDREŚs, note 2 supra.

6 CAL. WeLt. \& INST. CODE $\$ 5500$.

7 Id. § 5501 .

$8 I d . \S 5504$.
} 
a state hospital of the Department of Mental Hygiene designated by the court for observation and diagnosis for a period not to exceed 90 days ....

The superintendent of the hospital or person in charge of the county facility shall within 90 days cause the person to be examined and forward to the committing court his opinion as to whether or not the person is a sexual psychopath, whether or not he is a menace to the health and safety of others, and whether or not he will benefit by care and treatment in a state hospital, including therein a report, diagnosis and recommendation concerning the person's future care, supervision and treatment.

After receiving the report of the hospital superintendent, the court proceeds with the case. If the superintendent has reported that "the person is not a sexual psychopath or that he is a sexual psychopath but will not benefit by care and treatment in a state hospital," the person is returned to the court in which the criminal action was tried "to await further action with reference to such criminal charge." If, on the other hand, the superintendent indicates that the person is a sexual psychopath and could benefit from treatment in a state hospital, the court schedules a further hearing on the issue of sexual psychopathy.

Upon such further hearing the court nay make an order committing the person to the department for placement in a state hospital designated by the court for an indeterminate period, or may make other suitable disposition of the case. ${ }^{10}$

Criminal proceedings are thus suspended, and the person remains in the state hospital until such a time as the superintendent certifies that he

(a) has recovered from his sexual psychopathy to such an extent that in the opinion of the superintendent the person is no longer a menace to the health and safety of others, or (b) has been treated to such an extent that ... [he] will not benefit by further care and treatment in the hospital and is not a menace to the health and safety of others, or (c) has not recovered from his sexual psychopathy, and in the opmion of the superintendent the person is still a menace .... . [After (a) or (b) certification,] the coinmittimg court shall forthwith order the return of the person to said committing court and shall thereafter cause the person to be returned to the court in which the criminal charge was tried to await further action with reference to such criminal charge. ${ }^{11}$

II

CRITICISMS OF DEFINITIONS AND CONCEPTS

OF THE SEXUAI PSYCHOPATH ACT

A.

Use of Terms

1. Psychopath

The expression "psychopath" is not a proper, adequately descriptive,

${ }^{9}$ Id. $\$ 5512$.

$10 \mathrm{Ibid}$.

${ }^{11}$ Id. $\$ 5517$. (Emphasis added.) 
or sufficiently explanatory medical term, nor is it diagnostically or dynamically acceptable. Its use as a legal definition, under the guise of a medical diagnosis, is particularly unfeasible. Prolonged discussion in psychiatric circles about the usefulness of this concept has resulted in almost unanimous agreement to drop "psychopath" from medical terminology. This decision is a reflection of more advanced, dynamic psychiatric knowledge and often-repeated practical experience with the limited usefulness of the term even as psychiatric description. Hence, this term is no longer contained in the official nomenclature of the American Psychiatric Association; it is, in fact, used in modern times only colloquially, in sociological and legal jargon, rather than for medical or psychiatric purposes. The main objection to the use of the term "psychopath" is the realization that it is a "wastepaper" diagnosis, which designates a vast variety of conditions, while presumably referring to one definite disease picture. The Group for the Advancement of Psychiatry has correctly questioned the advisability of nosologic labels of mental disease for legal purposes, since if any medical term becomes "a part of public law such a term attains a fixity unresponsive to newer scientific knowledge and application."12 This is precisely what has happened to the term "psychopath"; it would, therefore, be objectionable as such, even if at the time of enactment of the Sexual Psychopath Act the tern had not fallen into general disrepute in the best-informed medical and psychiatric circles.

\section{Sexual Psychopath}

The concept "sexual psychopath" does not distinguish at all between the different types and degrees of so-called sexual psychopathy. It indiscriminately throws together such offenses as violent rape of children and exhibitionism, extreme brutality and the voyeurism of the "peeping Tom." Exhibitionism and voyeurism, for instance, usually affect persons who are incapable of any other criminal offense except repetition of the same compulsive or impulsive act. The percentage of such offenders who proceed to more dangerous forms of sexual or other crimes is considerably smaller than the percentage of violent criminals in the general run of the population.

As stated above, the sexual psychopath laws are specifically aimed at defendants who are not found to be legally insane. However, no real differentiation is made in these statutes between the mental disease or disorder which constitutes insanity and the mental disease or disorder which is a contributing factor to sexual psychopathy, as defined in section $\mathbf{5 5 0 0}$ of the Califorma Welfare and Institutions Code.

While, at one end of the behavior scale, the Sexual Psychopath Act does not differentiate between insanity and other mental disease not constitut-

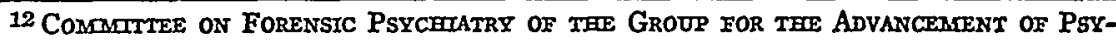
certatry, Psychiatricalty Deviated Sex OfFenders, Report No. 9 (1949). 
ing insanity, neither does it clearly differentiate, at the other end, between sexually deviant and normal sexual behavior. Only a very small group, numbering between five and ten per cent of all cases convicted of sex offenses, has been charged with sexual behavior which is naterially different from that of the rest of the population-that is, so far as the sexual element of the act itself is concerned the behavior is not related to such other criminal elements as force, brutality, fraud, or similar offenses. In fact, the purely sexual element, in the overwhelming majority of sex offenses, is found in practically all instances of normal sexuality, so that it can almost be concluded that the absence rather than the presence of such elements might give cause for suspicion of sexual pathology. Modern psychiatric and sociological literature has demonstrated the varying incidence of a large variety of sex practices in various geographical areas and under varying cultural and social conditions-all of these practices well within the limits of otherwise normal behavior.

The concept "sexual psychopath," as used in the Sexual Psychopath Act, is, therefore, meaningless and incomprehensible, or, in any case, far too broad and unspecific, since the present formulation does not permit evaluation of deviation to be made according to objective legal, medical or common-sense standards. This very indefimiteness permits and necessitates judgments that are left to the accidental, to relative morality, to the social and cultural bias, and to the unstated evaluation criteria of the judge, the superintendent, the staff of a state hospital, or the examining psychiatrist.

\section{Menace}

The use of the concept "menace" in the Sexual Psychopath Act is equally broad and unspecific, and similar criticism ean be applied to its use. A regulation of the State of California Department of Mental Hygiene calls attention to the relative meaning of the term "menace." The directive proceeds to consider the question of whether a "peeping Ton" or an exhibitionist should not be considered a lesser menace, or perhaps not a menace at all, if his act involves adults. ${ }^{13}$ There is a fine line between offensiveness and obnoxiousness on the one hand, and menace and danger on the other. But even if it were granted that such acts as indecent exposure constitute a menace, the precautionary measures should be related in their extent to the gravity of the danger, graduated by the interest at stake. To apply essentially umiform rules and identical methods of hospitalization to people who only challenge concepts of modesty and to people who seriously endanger the physical integrity of other human beings seems to be a serious legislative mistake.

13 Calif. Dept. of Mental Hygiene, Circ. Letter No. 2171 (1953). 
The inherent dangers in this lack of differentiation become compounded and multiplied if the term "menace" is taken to mean potential rather than actual threat. In this sense, every person, prior to his death, is a potential threat inasmuch as human behavior can be foreseen and predicted only with a certain probability, but not with certainty. Hence, nobody could possibly guarantee with complete assurance that any other human being would not, under certain circumstances, become a menace. The Sexual Psychopath Act permits and forces the evaluation of this danger to be made in an arbitrary, illegal, and unscientific mamer, notwithstanding the competence and conscientiousness of the person who actually makes the evaluation.

B.

\section{Determination of Sexual Psychopathy}

Due to the present lack of sufficient and adequately trained personnel, the 90-day period provided for observation and diagnosis in a county or state hospital is actually not being used for continuous and thorough study. The examination usually consists of one or two interviews by a psychiatrist, sometimes a series of psychological tests, and the rather routme observation of behavior on the ward. Therefore, the scientific validity of this method of determination is not basically different from or superior to the examination by court-appointed psychiatrists.

The examination by the two or three court-appointed psychiatrists is reduced in its validity by a number of controversial, arbitrary, or outright contradictory elements:

(a) The time allotted for a psychiatric examination (which may determine the disposition of the case for many years or even for a lifetime) is usually one or, at the most, two interviews of an hour to an hour and a half, for which a minimal compensation is paid.

(b) Due to the ambiguities and lack of medical definiteness in the term "psychopath," there are extremely wide variations and inconsistencies in the interpretation of the tern among various psychiatrists, who, by necessity, belong to widely different medical and psychiatric schools which reject this concept with greater or lesser repugnance. Also, as previously indicated, the terms "menace" and "threat" allow the same wide disparity and inconsistency im understanding and interpretation as does the term "psychopath." Furthermore, as also indicated previously, it is completely impossible to provide more than guesswork about the probability of a potential threat-even if one could define, for instance, what kind of threat a homosexual practicing with adults or an exhibitionist would constitute.

(c) All court psychiatrists have, verbally and in written form, been instructed by the court to disregard the question of guilt or innocence of 
the defendant before them and to assume the guilty verdict of the court or the jury as correct. These instructions of the court to the psychiatrists are, undoubtedly, proper and necessary, since the right of determination of guilt or innocence is constitutionally reserved to the court or the jury after due process of law and should not be relegated to a psychiatrist or any other type of expert. Yet, it is very often almost impossible for the psychiatrist, in spite of his own best intentions, not to consider the subject of guilt or innocence, since it so often constitutes the predominant, or even exclusive, thought content of the person he is examining. The psychiatrist, then, is placed in the absurd position of having to base his opmion largely on an evaluation of the statements of the defendant, while he is supposed to disregard the contents, implicit probability, truthfulness, etc., of these same statements. At least in one case in one of the authors' experience, a defendant had not only been innocently convicted of a crime which his brother had committed, but also had been unanimously declared a sexual psychopath by three examining psychiatrists, who, quite properly and according to instructions, refused to consider the evidence of the trial and canie to their conclusions on the basis of the type of offense the defendant was supposed to have committed.

Errors, of course, are possible in every procedure, but in this type of examination the psychiatrist is forced to arrive at a medical evaluation and psychiatric diagnosis while being prevented procedurally from doing anything else but either accepting the legal determination, regardless of his own possible doubts, or else re-evaluating the legal proceedings illegally and without proper safeguards.

C.

\section{Application of the Law}

After due commitment under the Sexual Psychopath Act, the patient is treated in a designated county or state hospital. Even in the best of these, due to limitations of personnel and resources, group psychotherapy is the only formal type of psychiatric treatment available; and ordinarily the patient must wait for weeks, sonietimes months, or often a year, before he can be placed in one of the overcrowded treatment groups. Furthermore, certain types of offenders-particularly those of advanced age, with mental deficiency, or with any one of a variety of organic conditions-cannot, for practical reasons, be engaged in group psychotherapy. Since no other kind of special psychiatric procedure can be offered except ward management and possibly occupational therapy, by necessity their treatment is, in all essentials, not different from that practiced in any prison with maximum 
security regulations. To the knowledge of the authors, there are in California state hospitals no regular facilities available for individual or any form of mtensive psychotherapy, which, according to modern psychiatric opinion, is im most cases the therapy of choice.

Furthermore, it becomes almost immediately clear to any but the mentally defective patient that a certain attitude on his part promotes or prevents an early acceptance in a treatment group and an early certification and possible discharge. All modern psychiatric research, as well as common sense, demonstrates that improvement or recovery from psychological disturbance, mamifested by behavior abnormalities, cannot be successfully achieved except under those conditions in which the behavior abnormalities have occurred and might reoccur. The treatment purpose which the legislation may have intended, though it permits neither any degree of personal freedom nor individualized types of therapy, is clearly less obvious to the offender than the punitive flavor of involuntary confinement under maximum security conditions. Therefore, quite naturally the treatment goal recedes in importance in the minds of the offenders, who feel themselves to be prisoners before they can realize their roles as patients. Hence, one meets a great number of offenders whose statements are, consciously or unconsciously, designed to meet the expectations of the authorities, who appear to them as jailors before they can be appreciated as doctors. This accounts for the extraordinary incidence of oral or written outpourings by offenders, fairly dripping with self-accusations calculated to demonstrate what the patient believes the psychiatrist will call "insight." These orgies of abject self-humiliation and self-accusation can be compared only with the Soviet type of "confession," but they are the foreseeable and unavoidable results of the regrettable and scientifically completely untenable practice of attributing undue importance to the patient's surface reactions. ${ }^{14}$

Discharge from the hospital and return to the court takes place as a result of an (a) or (b) certification by the superintendent. ${ }^{15}$ To the knowledge of the authors, there has not been an (a) certification in any case in the last few years, and quite understandably so, because no superintendent or psychiatrist can state defimitely that another person is no longer a "menace" to the health and safety of others, particularly not when the only

\footnotetext{
14 The denial by the patient, for instance, "that he has a problem" is often tantamount to a negative evaluation by the superintendent or the psychiatrist. But some patients will make defiant statements because they believe that any recognition of their problem will be considered as the equivalent of a confession in a criminal proceeding. In some such cases, the psychological defense mechanism of denial may be a prominent symptom and should be treated as such. But in a treatment setting where patients feel that only a certain type of response will be tolerated because any other leads to prolonged treatment-which also means prolonged incarceration for a period of several more years-no real remedy or cure for subtle, unconscious, repressed mechanisms can be expected, even under the most favorable conditions and the enthusiastic assistance of the professional personnel.

15 See italicized portion of text at note 11 supra.
} 
possibility of observation has been under such restricted circumstances as exist in a closed institution. One can only sympathize with the concern and reluctance of a number of responsible psychiatrists to assume, under such circumstances, the personal responsibility for release of the sex offender, even with a (b) certification. But, in view of the superficiality of the available methods of observation and study, is not the reluctance of the superintendent or psychiatrist to release a possibly dangerous person to the community a grave danger to protection of the rights of the individual? Furthermore, in considering this kind of favorable certification, a tremendous premium is put on a type of compliant, institutional "adjustment," which, according to the experience of penal and psychiatric authorities, indicates often the very opposite of a real and fundamental change.

The still positive (b) certification indicates that the patient has been treated to such an extent that, in the opinion of the superintendent, he will not benefit from further care and treatment in the hospital and is not a "menace" to the health and safety of others; (c) certification usually leads to imprisonment for a maximum period of time or referral to an institution for the criminally insane.

The psychiatric argument, supported by thousands of cases, that the real test as to improvement of the person predisposed to the commission of sexual offenses cannot be carried out in custody, is incontrovertible. At least in the later treatment stages, a certain amount of therapeutic latitude is essential. Only under parole, under close and expert supervision of a specifically trained supervising parole officer, with climical out-patient treatment, follow-up, etc., can any substantial improvement or cure be achieved or observed.

In addition, there is another procedural problem which should be raised. Is the testimony of a hospital superintendent admissible evidence in those many instances in which the superintendent has not seen the patient at all in psychiatrically adequate interviews and examination, but is actually reporting on the findings of his climical staff, frequently composed of doctors and other personnel in the training stage? Is such evidence not to be excluded as hearsay? ${ }^{16}$

\section{$D$.}

\section{Final Disposition}

Because the sexual psychopath proceedings are "civil" in nature and intended to be curative rather than punitive, the patient is returned to the

16 See, e.g., Bauman v. People, 274 P.2d 591 (Colo. 1954), where, in an analogous but not identical situation, it was deemed reversible error to admit testimony of a psychiatrist. The witness was a member of the staff of a psychopathic hospital and was present at a staff meeting where the patient's sanity was considered. His testimony that the staff decision was that the defendant was legally sane was deemed hearsay and thus inadmissible. See also Village of Ponca v. Crawford, 18 Neb. 551, 26 N.W. 365 (1886). 
court after treatment for resumption of the criminal proceedings. While most judges, in imposing sentence, take into consideration the prolonged enforced hospitalization, a strong minority of them feel that after the patient has been cured he still has to "pay his debt to society" to the full extent, and they often sentence him to a penal institution to atone for his crime. Thus, after the defendant first comes before the court and is found guilty of a sex crime, he is turned over to a hospital and, presumably, becomes a patient. Usually for many years all the resources of the state are strained in order to cure him of the disease or condition that was responsible for his deed. Then, after the superintendent has certified that treatment has been successful, the patient changes into a defendant again. After his successful cure or improvement he is now punished, often with the full severity of the law, because it has been stated definitely that the sexual psychopath proceedings are in addition to, not in lieu of, criminal prosecution.

What was conceived as a civil proceeding under the Sexual Psychopath Act has gradually evolved into a criminal proceeding, or its equivalent-so much so that the court is given the right to appoint a public defender and the district attorney may appear for the people.

Mr. Nichols, in discussing the legal question of whether the district attorney can appear in a civil proceeding, states that a sexual psychopath hearing is really a criminal proceeding which is called a civil proceeding, so that "quite a hybrid situation" exists in our sexual psychopath laws."

Possibly these procedural characteristics may not be decisive. However, the fact that sexual psychopath proceedings may lead to criminal prosecution, to involuntary hospitalization, or even to placement in a penal institution, leaves little doubt that this proceeding has all the dangers and consequences of a criminal trial. This was explicitly recognized in the Michigan case of People v. Frontczak. ${ }^{18}$ There a divided court, in holding unconstitutional Michigan's first statute respecting sexual psychopaths, stated that the exercise of the police power confining a person convicted of an overt sex deviation as a potential criminal-like offender was not a civil proceeding. It was deemed not comparable to proceedings to determine insanity. Yet California courts have repeatedly held that the sexual psychopath procedure is a civil proceeding and that provisions of the act are not unconstitutional. ${ }^{19}$

17 NICHOIS, ADDRESS, note 2 supra.

18286 Mich. 51, 281 N.W. 534 (1938).

10 People v. McCracken, 39 Cal.2d 336, 246 P.2d 913 (1952); In re Keddy, 105 Cal. App.2d 215, 233 P.2d 159 (1951). But see Gross v. Superior Court, 42 Cal.2d 816, 270 P.2d 1025 (1954), where the supreme court, speaking through Traynor, J., recognizes that defendant's liberty is at stake and that his rights need protection similar to that in a criminal case. 
III

\section{SUMMARY AND CONCLUSION}

"Sexual psychopathy" has been described as an inadequate, confusing, and obsolete medical term. In the sexual psychopath laws it is applied in a pseudo-legal sense-a discarded and discredited medical concept is substituted for a useful legal definition. The ambiguities, uncertainties, and arbitrariness arising from the use of this term and such other concepts as actual and potential "threat" and "menace" have already been discussed ${ }^{20}$ Provisions of the Sexual Psychopath Act cover indiscriminately the most severe cases of violent and dangerous criminal brutality, as well as relatively harmless instances of sexually deviant behavior which, in some form, also occur in the normal person. Some of these offensive habits never change or deteriorate, and they often constitute more a nuisance or an insult to certain moral views than a "menace."

Under prevalent conditions of examination and treatinent, valid and objective scientific criteria for commitment or for discharge of the patient do not exist. The relative uniformity of treatment of the most diverse conditions, vaguely and undefinably subsumed under the designation "sexual psychopath," is enforced necessarily by the lack of sufficient and adequately trained staff, and prevents any rational treatment approach or the obtaining of any useful research results as guidance for better treatment. The present set-up compels, for quite realistic reasons of early discharge, the stereotyped confession orgies of the more intelligent offenders-which are, of course, travesties of "insight" rather than expressions of it.

The law attempts to mix the contradictory and mutually exclusive elements of punishment and treatment. This absurdity culninates in the faulty timing of first attempting a psychiatric cure and improvement, although under most unfavorable circumstances, and then proceeding with punishinent. If punishment has to be retained at all costs, it would seem to make more sense first to punish and then to proceed with the cure.

Regardless of the fine legal distinctions between criminal and civil procedures and the controversial rulings on double jeopardy ${ }^{21}$ it seems evident that involuntary hospitalization in a maximum security hospital or penal institution, under inevitably poor or nonexistent treatment conditions, contains an overwhelmingly strong punitive element. There has, in our experience, never been the slightest doubt in the minds of any of the offenders or the law enforcement officers that this type of forced institutionalization is primarily punishment, regardless of its precautionary and therapeutic aspects, which is, of course, precisely why this legislation was passed in the

${ }^{20}$ See text at note 13 supra.

21 See text at notes 18 and 19 supra. 
first place. It is our conclusion that the present statutes, by attempting to serve punishment and treatment at the same time, accomplish neither the one nor the other to any satisfactory extent.

IV

\section{SUGGESTIONS AND RECOMMENDATIONS}

Theoretical analysis of the various problems and difficulties connected with the philosophy and the definitions of the sexual psychopath laws, and particularly years of experience with their practical application, have conclusively shown that a radical change is in order, because in their present form these sex laws create more confusion than clarification, more injustice than treatment facilities. Under the guise of being scientifically acceptable and progressive measures, they deprive the affected individual of his freedom, while they contribute little, if anything, to his possible rehabilitation and may prevent unore hopeful therapeutic measures. They add nothing to knowledge or research, and, particularly, they protect the community less, not more, than before this legislation.

Our suggestions are twofold and, in essense, very simple: (1) Complete repeal of the Sexual Psychopath Act; (2) An enlargement and eventual unification of all statutes and legislative acts concerned with degrees of responsibility, mental illness, mental defect, etc.

The Report of the Group for the Advancement of Psychiatry states that unlawful sexual acts must be recognized as surface manifestations of a more profound psychological disturbance, that in fact this symptom may be less significant than other pathological features of the total personality. ${ }^{22}$ The report continues: ${ }^{23}$

It is clear that in the legal process we should go beyond the symptomatic illegal act itself and assess the total personality to enable the courts to better achieve the aim of both community protection and individual treatment.

It is scientifically naive to classify a particular group of offenders according to one symptom of their illness and treat them differently from those whose different overt acts of deviant behavior may be the sign of the same mental disease or disturbance. While sexual delinquency can be considered prima facie evidence of personality maladjustment and possible underlying mental disorder, in the overwhelming majority of cases the sexual aspect of a crime does not in itself differ from actual nornal sexual behavior, which

22 Comomttee on Forenstc Psychitatry of the Group for the Advancencent of Psychiatry, Psychiatricaliy Deviated Sex Offenders, Report No. 9 (1949).

23 Ibid. 
is being judged on the basis of an archaic common law removed from the realities of modern life and human behavior.

The refreshing spirit of scientific courage, which partly motivated the first sexual psychopath laws, established the principle of treatment instead of punishment. This enlightenment, fortunately, is finding more and more legislative expression. In some jurisdictions a psychiatric examination and report is required for any person convicted of any offense including, but not confined to, sexual offenses. The repeal of the Sexual Psychopath Act need not, therefore, prevent a routine psychiatric examination of every sexual offender, as well as other offenders. In Massachusetts, for instance, the provisions of the Briggs Law, ${ }^{24}$ passed in 1921, require that the state's Department of Mental Disease give a mental examination and report to the court on the mental condition of anyone indicted for a capital offense, or with a record of recidivism. And in the Pennsylvania Mental Health Act of 1951 the following provision appears: ${ }^{25}$

(c) On the report of the exammer that the defendant is so mentally ill or defective that it is advisable for his welfare or the protection of the community that he be committed to other than a penal or correctional institution, the court may commit him, on a form prescribed by the department, to a State institution for the care of such mental cases in lieu of sentence to a penal or correctional institution, and direct his detention until further order of the court. If the examiner's report indicates no such mental ilhess or deficiency, he shall be sentenced as in other cases.

A procedure of such a type, while not singling out any particular-often purely accidental-symptom or group of symptoms, such as the sexual ones, in the manifest and overt acts, provides maximum protection for the community because the patient can be observed, diagnosed and treated under optimal conditions of security for as long a period of time as necessary. Although such an act might not automatically exclude the results of error and negligence, it would render the detention clearly protective, diagnostic, and therapeutic rather than punitive in a disgnised form, the result of the present legislation under which the patient is returned to continued criminal prosecution after the improvenent or cure has been accoinplished.

The suggested procedure could be easily integrated with the modern developments and changes in the determination of insamity. In the recent case of Durham $v$. United States, ${ }^{26}$ after a most enlightened review of the history of our present concept of criminal responsibility, the court adopted the rule that an accused is not criminally responsible if his unlawful act is

24 Mass. ANN. LAws c. 123, § 100A (1953).

25 PA. Stat. Aivn. tit. 50, 1223 (c) (1954). (Emphasis added.)

${ }^{26} 214$ F.2d 862 (D.C. Cir. 1954). See 22 U. C\#I. L. REv. 317-404 (1955) for an extensive critique of the Durham case. 
the product of mental disease or mental defect. Disease is defined therein as a condition which is considered capable of either improving or deteriorating; and defect is defined as a condition which is not considered capable of either improving or deteriorating and which may be either congenital, the result of injury, or the residual effect of a physical or mental disease.

Since this decisive forward step has been taken in one jurisdiction in the United States, it may be hoped that in the not-too-distant future a comprehensive reform of the criminal law will give a place of central importance to the question of the various degrees of responsibility, impaired or disturbed mental capacity, mental defect, and mental illness, which would, of course, amply cover all those cases now falling under the Sexual Psychopath Act.

A detailed discussion of the principle of criminal responsibility in general would, of course, go beyond the framework of the present article. But it seems evident that any attempts to revise certain aspects of our present sex legislation, in the manner suggested here, will inevitably challenge many of the basic assumptions of criminal law, particularly the concept of criminal responsibility. In this connection, it is significant that at the present time members of the American Law Institute are deliberating and have tentatively formed a new Model Penal Code, ${ }^{27}$ which contains far-reaching changes in the concept of criminal responsibility, even beyond the enlightened formula of the Durham case, and which gives particular attention to those provisions of the code which deal with sex offenses.

In the meantime, public education should be utilized in an attempt to prevent the effects of the unholy coalition of vengeance tendencies with sexual excitement, which leads to the promulgation of irrational sex legislation.

The sexual psychopath legislation has actually only aggravated the existing hardships and made reform doubly necessary. Repeal of the act would at least have the advantage of discontinuing the deception of the community and "experts" who believe that the long-needed reform in regard to sex crimes has already taken place. With such repeal, increased attention in the near future to new legislation concerning all mental diseases, aberrations, and defects is most earnestly urged.

27 MOdeI PENaI Code (Tent. Draft 1955). 